\title{
APIÁRIO ORGANIZACIONAL DO MEIO AMBIENTE: INSTRUMENTO DE MENSURAÇÃO DO NÍVEL DE GESTÃO AMBIENTAL
}

\author{
Márcio Henrique Marques da Cunha \\ Mestre em Administração de Empresas \\ Universidade de Fortaleza Fortaleza - CE - Brasil \\ facilacessos@yahoo.com.br https://orcid.org/0000-0002-4568-4480 \\ Oderlene Vieira de Oliveira \\ Doutora em Administração de Empresas \\ Universidade de Fortaleza Fortaleza - CE - Brasil \\ oderlene@hotmail.com http://orcid.org/0000-0002-5083-3727
}

\section{RESUMO}

Com o objetivo de propor um instrumento de mensuração do nível de gestão ambiental de pequenas e médias empresas, adotou-se uma abordagem metodológica qualitativa, fazendo uso de pesquisa exploratória, descritiva e documental. A pesquisa desenvolveu-se em duas fases. Na primeira fase, fez-se levantamento dos documentos existentes que dão orientação sobre a preservação do meio ambiente, com o intuito de selecionar os indicadores de gestão ambiental; e na segunda fase, o foco foi no teste de viabilidade do instrumento proposto. Os resultados possibilitaram averiguar que as dimensões e itens do instrumento proposto possibilitam a mensuração do nível de gestão ambiental das pequenas e médias empresas de qualquer seguimento, tendo em vista a sua aplicabilidade em empresas do segmento indústria, comércio e serviços. Fortalecendo assim, a credibilidade do instrumento e seu construto. Portanto, concluiu-se a pesquisa com a proposição de um instrumento de mensuração do nível de gestão ambiental de pequenas e médias empresas, denominado Apiário Organizacional do Meio Ambiente.

Palavras-chave: Gestão Ambiental. Estratégia Ambiental. Meio Ambiente. Indicadores.

\section{ORGANIZATIONAL APIARY: PROPOSING AN ENVIRONMENTAL MANAGEMENT TOOL}

\begin{abstract}
The aim of this study is to propose an instrument for measuring the environmental management level of small and medium-sized companies. To that end, this study adopted a qualitative approach including exploratory, descriptive, and documentary research. This study encompassed two phases. The first phase identified the existing documents that provide guidance on the environment preservation, aiming at selecting indicators of environmental management. The second phase involved testing the feasibility of the proposed instrument. Findings indicate that the dimensions and items of the proposed instrument can measure the environmental management level of small and medium-sized companies in any sector, considering its applicability in companies that are part of the industry, commerce, and service sectors. As a result, this enhances the credibility of the instrument and its construct. This study thus offers an instrument for measuring the environmental management level of small and medium-sized companies, which has been named as the Organizational Apiary of the Environment.
\end{abstract}

Key words: Environmental Management. Environmental Strategy. Environmen. Indicators.

Data da submissão: $14 / 05 / 2019$

Data de aceite: $22 / 01 / 2020$ 
Apiário organizacional do meio ambiente: instrumento de mensuração do nível de gestão ambiental

\section{INTRODUÇÃO}

Existe uma expectativa crescente baseada em atitudes e normas sociais de que as empresas tomarão a iniciativa de querer minimizar os danos ambientais causados, já que a má conduta ambiental é passível de críticas na mídia (Tang \& Tang, 2013; Xu, Zeng, Zou, e Shi, 2014) causando dano à reputação delas (Zou, Zeng, Zeng, \& Shi, et al., 2015). No entanto, embora um bom desempenho ambiental esteja em conformidade com as normas sociais e éticas, e assim percebido pelo público em geral, os comportamentos ambientais negativos ainda não incorrem em fortes penalidades nos regulamentos governamentais existentes, e nem o desempenho ambiental favorável consegue aumentar o valor de mercado da empresa (Zou, Zeng, \& Lin, 2015). Mas, para alguns pesquisadores, a exemplo de Villiers, Naiker e Van Staden (2011), a gestão ambiental tornou-se um caminho importante para as empresas ganharem vantagem competitiva.

Estudos ressaltam que um desempenho ambiental sólido melhora não somente a reputação corporativa (Melo \& Garrido-Morgado, 2012), como também a produtividade (Galdeano-Gómez, Céspedes-Lorente, \& Martínez-Del-Rio, 2008); reduz os custos de financiamento (Sharfman \& Fernando, 2008) e fortalece as relações dos stakeholders (Bansal, 2005). Por outro lado, o mau desempenho ambiental pode impor custos adicionais, levando a uma queda no valor de mercado (Dasgupta et al., 2006) e desafios à legitimidade corporativa (Berrone \& Gomez-Mejia, 2009; Villiers, Naiker, \& Van Staden, 2011). Assim, os investimentos das empresas na área ambiental, antes visto apenas como custos, passaram à serem vistos como estratégicos à atuação da empresa, gerando benefícios sociais, ecológicos e econômicos (Abreu et al., 2004), além de valorizar o produto como sustentável.

A estratégia ambiental corporativa está profundamente enraizada em um ambiente institucional em que os diversos stakeholders representam um mecanismo de punição e podem representar ameaças à legitimidade ambiental de uma empresa (Liu, Lu \& Chizema, 2013). De acordo com Berrone e Gomez-Mejia (2009) a pressão institucional é uma força motriz importante para as empresas implementarem estratégias ambientais. A legitimidade resultante está associada dentre outras coisas a reputação corporativa e a acessibilidade de recursos (Bansal, 2005; Berrone \& Gomez-Mejia, 2009). Nesse contexto, Fernández-Kranz e Santaló (2010) ressaltam que, do ponto de vista estratégico, as decisões sobre investimentos ambiental são um trade-off entre custos e potenciais benefícios.

Inerente às discussões interessadas a um desenvolvimento empresarial sustentável permeia a ideia da ecoeficiência. Ser eficiente é uma prioridade para qualquer organização, em especial para as pequenas e médias empresas. Se simultaneamente ao desenvolvimento de maior valor econômico para a organização, criarem-se mecanismos para redução dos impactos das atividades empresariais no ambiente; e mecanismos para uma utilização mais responsável dos recursos produtivos, atinge-se um estágio maior de eficiência, no caso, a ecoeficiência (Bleischwitz, 2003). Considerando que, tais alterações são importantes e inevitáveis para a sociedade, não há outra escolha por parte das empresas, senão munir-se de recursos para satisfazer essas expectativas (Bertolini \& Possamai, 2005).

$\mathrm{Na}$ Academia foi detectado alguns instrumentos de avaliação do nível de consciência verde de pessoas, como o Pentáculo do Meio Ambiente (Santos, 2007) - instrumento de mensuração do grau de consciência ambiental, do consumo ecológico e dos critérios de compra dos consumidores (Vieira, 2016), mas não foi detectado nas principais bases de dados referenciais pesquisadas até o final do ano de 2018, instrumento de mensuração do nível de consciência ambiental no contexto organizacional. Assim, frente a essa lacuna e a crescente pressão dos consumidores e da sociedade como um todo por empresas mais responsáveis ambientalmente, emergiu o interesse na realização desta pesquisa, que tem como objetivo propor um instrumento de mensuração do nível de gestão ambiental de pequenas e médias empresas. Já os objetivos específicos consistem em: 1) identificar as dimensões-chave de preservação do meio ambiente no contexto organizacional das pequenas e

Revista de Gestão Social e Ambiental - RGSA, São Paulo, v. 13, n. 3, p. 24-43, set./dez. 2019. 
médias empresas; 2) testar a viabilidade do instrumento proposto; e 3) avaliar o perfil do estilo de gestão ambiental de pequenas e médias empresas dos segmentos indústria, comércio e serviço.

Acredita-se que esse instrumento de mensuração do nível de gestão ambiental contribuirá para avaliar as ações e resultados em relação ao comportamento em gestão ambiental das pequenas e médias empresas, como uma ação para a construção de uma nova sociedade empresarial. As análises decorrentes dos dados coletados pelo instrumento, permitirá refletir sobre como as empresas poderão avaliar sua gestão, ações e resultados com foco no meio ambiente, indo da sua concepção, implantação e desenvolvimento a partir da perspectiva das estratégias ou até mesmo das suas obrigações legais.

\section{GESTÃO AMBIENTAL EMPRESARIAL}

As corporações são criações sociais, e argumenta-se que a sua existência depende da vontade da sociedade em continuar permitindo-lhe operar (Mahadeo et al., 2011). A ideia de contrato entre as organizações e os membros da sociedade sugere que, apesar de o lucro ser o principal objetivo de uma empresa (Andrade \& Rosseti, 2012), essa tem a obrigação de agir de maneira ambientalmente responsável.

Não são raros os gestores que falam em um trade-off entre desempenho socioambiental e financeiro (Ceretta et al., 2009). Além disso, a competitividade, também tem uma abordagem estratégica em um ambiente marcado pela diferenciação (Porter \& Kramer, 2006), no qual os clientes esperam poder interagir com as organizações, exigindo dessas uma postura ética e ecologicamente responsável (Tachizawa, 2010) e em que a legislação ambiental e o uso mais eficiente de matérias-primas, materiais e energia influenciem diretamente na capacidade de uma empresa de competir no mercado.

Tachizawa (2010) destaca que a gestão ambiental acabou tornando-se um importante instrumento gerencial para capacitação e criação de condições de competitividade para as organizações, qualquer que seja o seu segmento econômico. Assim, à medida que as empresas vão compreendendo e integrando as questões ambientais a um processo mais amplo de tomada de decisão, a gestão ambiental pode levar a empresa a transformar muitas dessas questões em estratégias para o alcance de vantagem competitiva em relação à sustentação futura (Nossa, 2002).

\subsection{Estratégia ambiental corporativa e iniciativa ambiental corporativa}

Quando se trata de estratégia, o meio ambiente é encarado como elemento de competitividade extra custos (Corazza, 2016). A introdução da gestão ambiental nas empresas se faz com o objetivo inicial de prevenir o impacto ambiental e de antecipação com respeito à evolução da regulamentação, a que Godard (1993) chamou de gestão antecipada de uma legitimidade contestável, e a seguir, com a finalidade de prospecção e desenvolvimento de novas oportunidades de negócio no sentido do que Porter e Van Der Linde (1995) consideram como a construção de uma competitividade assegurada pelos investimentos na área ambiental.

Além do desempenho financeiro (Conyon \& He, 2011), o desempenho ambiental das empresas também depende da equipe de gerenciamento (Berrone \& Gomez-Mejia, 2009). Sem o apoio da equipe gerencial, a orientação ambiental interna fornece resultados menos significativos do que o esperado (Paillé et al., 2014). Assim, os principais executivos influenciam as estratégias ambientais das empresas. E colocar essas estratégias em prática requer grande esforço em termos de redesenho de produção, inovação técnica, equipamento multifuncional e coordenação de funcionários (Berrone \& Gomez-Mejia, 2009).

A concorrência industrial é outro fator que influencia o comportamento corporativo socioambiental responsável (Mcwilliams, Siegel, \& Whight, 2006; Zhang et al., 2010). Os estudos mostram que a intensidade da concorrência industrial tem uma influência pronunciada sobre a 

benefícios que as empresas podem obter com ela (Fernández-Kranz \& Santaló, 2010; Mcwilliams et al., 2006; Neville, Bell, \& Menguç, 2005).

A concorrência industrial intensifica a dificuldade de explorar o mercado e de aumentar a rentabilidade (Acquaah, 2003) e impulsiona as empresas a gastar recursos com a finalidade de reduzir custos (Spence, 1984). Como consequência, uma concorrência mais forte pode influênciar as empresas a reduzir os recursos que desviam para objetivos socialmente benéficos (FernándezKranz \& Santaló, 2010) a favor da maximização dos lucros. Isto é especialmente provável em um ambiente institucional em que a prática de má conduta ambiental traz uma penalidade negligenciável.

De acordo com Paulraj (2009) as estratégias ambientais são muitas vezes motivadas por considerações legislativas ou competitivas, em vez de fazer parte de valores mais fundamentais dentro da empresa. Como resultado, muitos esforços ambientais tendem a ser desconectados tanto do sistema de controle geral como do planejamento estratégico dentro das organizações (Jansson, Nilsson \& Rapp, 2000).

Nesse sentido, Haigh e Griggths (2009) ressaltam que a direção dos esforços ambientais de uma empresa tem consequências de longo alcance, tanto para os aspectos ambientais que a empresa leva em conta quanto para os diversos stakeholders (Haigh \& Griffths, 2009). Do ponto de vista dos recursos, o fluxo de material, conhecimento e experiências, relacionamentos, comunicações e cooperação e controle podem ser considerados como os aspectos fundamentais de uma estratégia ambiental efetiva; outro aspecto importante é a consistência entre essas diferentes partes de uma estratégia ambiental (Rodrigues, 2015).

Apesar de os investimentos na gestão ou nos programas ambientais serem caros e, no curto prazo, não levarem a resultados superiores. Em caso de ausência ou baixo nível de divulgação, os stakeholders tendem a assumir que a estratégia ambiental atual adotada pela empresa seja inferior (Clarkson et al., 2011; Verrecchia, 2001) e isso impacta negativamente na imagem da empresa.

Frente a esse contexto, a FQN (2016) ressalta que, para apoiar no processo de acompanhamento da evolução da implementação de estratégias ambientais é de fundamental importância medir-se os resultados de forma sistemática e estruturada, ou seja, que se faça uso de indicadores. De acordo com Fernandes (2004) e Goellner, Jappur e Prado (2019), o uso de indicadores auxilia no estabelecimento da quantificação de um processo, sinalizando como ele se encontra e em que estágio ele está. Fernandes (2004) ainda ressalta que, devido a relevância e a importância de um indicador para a empresa, são necessários cuidados quando do estabelecimento da coleta e tratamento de dados, que constituem a base para a formação de um indicador.

Deponti et al. (2002) e Goellner, Jappur e Prado (2019) apontam para determinadas características que devem ser observadas na construção de indicados. Assim, um indicador deve: a) possuir significância para um julgamento do processo; b) ser objetivo, coerente e válido; c) ser flexível a mudanças do tempo e alterações dos processos; d) estar localizado em aspectos práticos, mostrando facilidade para o entendimento e que colabore para a participação das pessoas envolvidas no processo de mensuração; e) ter um foco integrador, que demonstre informações concisas sobre os vários aspectos do processo; f) ser de mensuração facilitada, fundamentado em informações prontamente disponíveis e de baixo custo; g) que permita uma extensa participação dos atores envolvidos na sua definição; e h) que permita uma relação com outros indicadores, facilitando a interação entre eles.

Nesse sentido, aborda-se na próxima subseção as orientações que versam sobre a preservação do meio ambiente e que serviram de base para o desenvolvimento do instrumento proposto nesta pesquisa.

\subsection{Orientações que versam sobre a preservação do meio ambiente}


As empresas têm buscado encontrar métodos, processos ou ferramentas que auxiliem a diminuir os impactos negativos de suas atividades, preservando o meio ambiente. Com isso, os empresários vem trabalhando meios de reduzir tais efeitos por intermédio de diversas abordagens, como a redução dos custos, selos verdes, certificações etc (Santana, 2008).

Luo (2006) ressalta que as empresas devem ser competentes para demonstrar ao mercado que suas práticas não são prejudiciais para o meio ambiente. Além do mais, para competir efetivamente e atender as expectativas de responsabilidade, a informação deve ser comunicada aos stakeholders, o que normalmente se dá por meio de relatórios de sustentabilidade. Nesse sentido, Rodrigues (2014) ressalta que há empresas que possuem apenas um engajamento socioambiental parcial em seus relatórios.

No Brasil, o processo de relato é voluntário, e as organizações podem elaborar o seu próprio modelo de relatório de sustentabilidade. No entanto, já se observam avanços no estabelecimento de padrões de divulgação de informações ambientais, por meio da utilização de indicadores específicos, desenvolvidos por entidades preocupadas com o tema (Nossa, 2002). A exemplo da Global Reporting Iniciative (GRI), do Instituto Brasileiro de Análises Sociais e Econômicas (Ibase), e do Instituto Ethos de Empresas e Responsabilidade Social (ETHOS). Como também dos Princípios da AccountAbility para o Desenvolvimento Sustentávele e da norma internacional ISO 14001.

A Global Reporting Initiative (GRI) é uma organização não governamental internacional, cuja missão é desenvolver e disseminar globalmente diretrizes para a elaboração de relatórios de sustentabilidade utilizadas voluntariamente por empresas do mundo todo. Tem o modelo de relatório de sustentabilidade com maior credibilidade no cenário internacional, que contém indicadores de desempenho Econômico, Social e Ambiental (GRI, 2015). A dimensão ambiental da sustentabilidade diz respeito aos impactos da organização sobre ecossistemas, incluindo aspectos bióticos e abióticos (solo, ar e água). A categoria ambiental abrange impactos relacionados a insumos (energia e água) e saídas (emissões, efluentes e resíduos). Ela abrange, também, impactos relacionados à biodiversidade, aos transportes e a produtos e serviços, bem como a conformidade com leis e regulamentos ambientais e gastos e investimentos na área ambiental (GRI, 2015).

Já o Instituto Brasileiro de Análises Sociais e Econômicas (Ibase) é uma organização de cidadania ativa, sem fins lucrativos. Efetivada a partir de 1981, foi fundada após anistia política por Hebert de Souza, e os companheiros de exílio Carlos Afonso e Marcos Arruda (IBASE, 2003). Em 1998, para estimular o uso do Balanço Social foi criado o Selo Balanço Social IBASE/Betinho. Em 2006, o IBASE deu início ao processo de consulta pública, para assim, analisar com mais propriedade quais empresas solicitantes do Selo teriam credibilidade para usá-lo. Por meio dessa metodologia a social civil pode opinar ou fazer denúncias sobre os balanços apresentados (Silva et al., 2012).

O Instituto Ethos de Empresas e Responsabilidade Social é uma organização nãogovernamental criada com a missão de mobilizar, sensibilizar e ajudar as empresas a gerir seus negócios de forma socialmente responsável, tornando-as parceiras na construção de uma sociedade sustentável e justa (ETHOS, 2004). O Instituto é um polo de organização de conhecimento, troca de experiências e desenvolvimento de ferramentas para auxiliar as empresas a analisar suas práticas de gestão e aprofundar seu compromisso com a responsabilidade social e o desenvolvimento sustentável (ETHOS, 2016). Os indicadores ETHOS para Negócios Sustentáveis e Responsáveis do ano de 2016 trouxe quatro principais dimensões que se dividem em temas, subtemas e indicadores. As quatro dimensões são: visão estratégica; governança e gestão; dimensão social; e dimensão ambiental. A quarta dimensão, que é a ambiental, trata das responsabilidades da empresas sobre os impactos da sua produção e de seus fornecedores no meio ambiente (ETHOS, 2016).

Os Princípios da AccountAbility para o Desenvolvimento Sustentável surgiram pela primeira vez na AA1000 AccountAbility Framework Standard, publicada em 1999. Durante o período de consulta para o desenvolvimento da primeira edição da AA1000 Assurance Standard, publicada em 2003, os princípios foram alvo de um significativo debate e revisão. O resultado foi o compromisso 
com a inclusão baseado nos três princípios, da Relevância, da Abrangência e da Responsabilidade. Estes princípios estiveram na base da AA1000 Assurance Standard publicada em 2003 AA1000AS (2003); e da AA1000 Stakeholder Engagement Standard publicada em 2005 AA1000SES (2005). Foram posteriormente clarificados numa nota de orientação sobre a aplicação dos princípios em relação à AA1000AS (2003), publicada em 2006 (ACCOUNTABILITY, 2008).

A ABNT NBR ISO 14001 é a versão brasileira da norma internacional ISO 14001 tendo em vista que NBR é a sigla para Norma Brasileira que é aprovada pela Associação Brasileira de Normas Técnicas (ABNT). Já a expressão ISO refere-se a Organização Internacional de Normatização, responsável por desenvolver normas, testes e certificação para o encorajamento do comércio de bens e serviços. É uma norma que especifica os requisitos de um Sistema de Gestão Ambiental e permite a uma organização desenvolver uma estrutura para a proteção do meio ambiente e rápida resposta às mudanças das condições ambientais. A norma leva em conta aspectos ambientais influenciados pela organização e outros passíveis de serem controlados por ela.

To \& Lee (2014) e Corazza (2016) explanam que a aplicação dos requisitos da ISO 14001 define a política ambiental, planos e ações da abordagem estratégica das questões ambientais adotadas pelas empresas. Já Marimon, Casadesús e Heras (2010) e Marimon, Llach e Bernardo (2011) ressaltam como outra abordagem estratégica na difusão da norma ISO 14001, a análise comparativa do nível de intensidade da certificação das principais nações. Nesse sentido Singh, Jain e Sharma (2015) ressaltam que seja considerada no seu escopo estratégico ou na disseminação mundial, a ISO 14001 tem-se mostrado fundamental em termos de sua relação direto com a imagem, compliance e prevenção de incidentes ambientais.

\section{METODOLOGIA}

Adotou-se uma abordagem metodológica qualitativa (Strauss \& Corbin, 2008), do tipo exploratória, descritiva (Collis \& Hussey, 2005) e documental (Patton, 2002). Exploratória e documental na fase de construção do instrumento e descritiva na fase de validação e aplicação do instrumento.

A pesquisa se deu em duas fases. Na primeira fase fez-se um levantamento dos documentos existentes que orientam sobre a preservação do meio ambiente, com o intuito de selecionar os indicadores de gestão ambiental; e na segunda fase, o foco foi no teste de viabilidade do instrumento proposto.

A primeira fase iniciou com a seleção de documentos que orientam a elaboração de relatórios de sustentabilidade, tais como Balanço Social, SA800, AA1000, GRI-G4, dentre outros, que listam práticas de gestão ambiental passíveis de serem adotadas pelas pequenas e médias empresas. Nesta fase, também buscou-se identificar as dimensões-chave que iriam compor o instrumento de mensuração do nível de gestão ambiental das empresas, intitulado Apiário Organizacional do Meio Ambiente. Para analisar os dados dos documentos, utilizou-se a Análise de Conteúdo, proposta por Bardin (2016). A autora ressalta que, ao iniciar a pré-análise dos dados é necessário selecionar alguns recursos de organização, como forma de nortear as interpretações das informações. Tais recursos foram classificados de acordo com as regras da homogeneidade, representatividade e pertinência (Bardin, 2016). Na Análise de Conteúdo foi empregado como regra de enumeração a presença ou ausência do indicador das subdimensões das práticas adotadas pelas organizações.

O recolhimento inicial das variáveis perfez um total de nove dimensões, conforme exposto no Quadro 1, que resultou em um primeiro questionário. 
Quadro 1 - Dimensões e subdimensões de análises

\begin{tabular}{|l|l|}
\hline \multicolumn{1}{|c|}{ Dimensões } & \multicolumn{1}{c|}{ Subdimensões } \\
\hline Conformidade & $\begin{array}{l}\text { Leis } \\
\text { Regulamentos }\end{array}$ \\
\hline Insumos & Energia \\
& Água \\
\hline Biodiversidade & Impactos ambientais(Fauna, Flora, Solo) \\
\hline \multirow{5}{*}{ Saídas } & Emissões de gases \\
& Emissões efluentes \\
& Emissões de resíduos \\
& Emissões de poluentes \\
\hline Produtos e Serviços & Recuperação de embalagens \\
\hline Investimentos & Investimentos em proteção ambiental \\
\hline Fornecedores & Avaliação de fornecedores \\
\hline Queixas e Reclamações & Avaliação de queixas e reclamações \\
\hline Resultados & Avaliação dos resultados \\
\hline
\end{tabular}

Nesse questionário, pretendeu-se recensear as 9 dimensões identificadas fazendo uso do método de Multiplicação Matricial Aplicada a uma Classificação (MICMAC), que consiste em inserir em um quadro de dupla entrada, denominado de matriz estrutural, os escores dados pelos especialistas visando identificar as dimensões influentes e dependentes, e a partir daí, as dimensõeschave. Contou-se com o apoio dos softwares Macrosoft Office Excel e MICMAC, da Lipsor.

De acordo com Godet (2000), a utilização do método MICMAC possibilita reduzir a complexibilidade do sistema por meio da identificação das dimensões-chave. A aplicação do método MICMAC deu-se em quatro etapas:

$1^{a}$ etapa - caracterizada pela exploração do tema em discussão, na qual cada indivíduo contribui com informações adicionais que considera pertinente

Nesta etapa, definiu-se como objetivo a inserção, exclusão e/ou realocação por especialistas dos indicadores de desempenho ambiental, selecionados previamente com base em documentos e relatórios que orientam a elaboração de relatórios de sustentabilidade. Nesse sentido, os especialistas consistiram em professores doutores, estudiosos no tema Gestão Ambiental, bem como profissionais que atuam na área. Essa etapa deu-se por meio de entrevistas, que foram realizadas na primeira quinzena de dezembro de 2018, e contou com o apoio de seis especialistas. O perfil dos especialistas que emitiram o parecer e opinaram para validar o instrumento foi composto por: um perito em gestão ambiental; dois fiscais da Secretaria de Urbanismo e Meio Ambiente; dois fiscais da Secretaria do Meio Ambiente; e um empresário ganhador de um prêmio de excelência em gestão organizacional e ambiental.

$2^{\mathbf{a}}$ etapa - é o momento em que o grupo de especialistas logra uma compreensão das questões. Inicia-se a elaboração do questionário da pesquisa

As dimensões utilizadas no questionário tiveram como objetivo identificar o grau de alinhamento dos especialistas com o instrumento proposto de forma a validar aspectos estruturais e funcionais do modelo, e também coletar conhecimento adicional em relação ao contexto onde o instrumento estará inserido. Ressalta-se que o termo "dimensão" se utiliza aqui para referenciar um elemento que pode ser manipulado, em menor ou maior grau no modelo. $\mathrm{O}$ termo não se refere aqui a uma variável quantitativa e ou matemática, na concepção formal desses tipos de variáveis. Para cada dimensão foram atribuídas afirmativas associadas a gestão ambiental dentre das organizações que poderá ser aplicada de forma individual e/ou em grupo com o propósito de avaliar as práticas e comportamentos relacionados às questões ambientais. Esse tipo de instrumento, de acordo com Santos (2007), não busca culpado, visa apenas uma avaliação no sentido de possibilitar uma maior inserção na preservação do meio ambiente. E por essa razão, práticas tais como, preservação da biodiversidade, redução do uso de recursos naturais, reuso de água, dentre outras fizeram parte do instrumento de mensuração. Pretendeu-se destacar práticas voluntárias ou compulsórias que 
Apiário organizacional do meio ambiente: instrumento de mensuração do nível de gestão ambiental

influenciam nas questões de conservação, preservação, envolvimento, discussão, engajamento e valoração do meio ambiente.

$\mathbf{3}^{\mathbf{a}}$ etapa - seleção dos especialistas

Nesta etapa foram selecionados os especialistas da área de gestão ambiental empresarial para participarem do processo respondendo o questionário. $\mathrm{O}$ anonimato dos participantes foi garantido, para que pudessem expressar suas opiniões livremente, sem ter influência de outros participantes (MILLER, 2001). Nessa fase, buscou-se atentar para o exposto por Wright e Giovinazzo (2000), que mencionam que 5 a 10 especialistas é considerado um bom número, o suficiente para gerar informações relevantes. Assim, a população-alvo compreendeu seis especialistas das Secretarias de Urbanismo e Meio Ambiente, para os quais foi encaminhado o questionário. O questionário foi disponibilizado em documento word ao qual os especialistas tiveram acesso por meio de correio eletrônico (e-mail), que seguiu juntamente com uma cartaconvite, em que se explicava a relevância do tema e da pesquisa e as contribuições acadêmicas e gerenciais que iriam decorrer dela. $\mathrm{O}$ preenchimento do questionário consistia em quantificar o nível de adoção das práticas ambientais por meio de preenchimento de forma qualitativa, em que, para cada par de dimensões, o perito deveria colocar as seguintes questões: 1) Existe relação direta entre a dimensão 1 e a dimensão 2? Se "Não", deveria atribuir a nota "0"; se "Sim", faria a segunda pergunta: 2) A relação existente é fraca (1), moderada (2), forte (3) ou potencial (4)?

$4^{\text {a }}$ etapa - avaliação final

Buscou-se analisar todas as informações reunidas e os resultados obtidos com a retroalimentação para propor o instrumento de mensuração de Gestão Ambiental. A tabulação dos questionários recebidos possibilitou identificar as dimensões-chave Para cada dimensão do Apiário existem quatro questionamentos, que são avaliados por meio de uma escala de 0 a 3 , sendo:

- $\quad 0$ - representado pela alternativa "a" e sinalizando ser uma prática que não faz parte do dia-a-dia da empresa. Como "0" não pontua, na Figura 1 a empresa permanece no centro do Apiário Organizacional;

- 1 - é representado pela alternativa "b" e sinaliza ser uma prática que às vezes faz parte do dia-a-dia da empresa. A empresa já consegue atingir o primeiro degrau na adoção de práticas de gestão ambiental na Figura 1;

- $\quad 2$ - é representado pela alternativa "c" e sinaliza que a prática quase sempre faz parte do dia-a-dia da empresa. Com esse nível de adoção em uma prática a empresa já atingi o segundo degrau na Figura 1; e o

- $\quad 3$ - é representado pela alternativa "d" em que a empresa afirma ser uma prática que verdadeiramente faz parte do dia-a-dia da empresa. E nessa situação a empresa atingi o topo do Apiário, simbolizado pela letra "d" na Figura 1.

A tabulação dos questionários recebidos possibilitou identificar as dimensões-chave por meio de uma matriz de dupla entrada. O processo resultou na seleção de 6 dimensões: 1) conformidade; 2) insumos; 3) saídas; 4) mecanismos de queixas e reclamações relacionadas a impactos ambientais; 5) produtos e serviços; 6) insumos. De posso das dimensões-chave elaborouse o segundo instrumento de coleta de dados que possibilita mensurar o nível de gestão ambiental de pequenas e médias empresas.

$\mathrm{Na}$ seleção da escala de resposta utilizada no instrumento proposto, atentou-se para o exposto por Campos e Melo (2008), de que é fundamental ser observado que um indicador muito complexo ou de difícil mensuração não é adequado, pois a complexidade pode inviabilizar sua operacionalização; como também seguiu-se a estruturação do Pentáculo do Meio Ambiente proposto por Santos (2007), só que ajustando para o contexto organizacional. Assim, adotou-se uma escala de 0 a 3, que possibilitará avaliar os quatro questionamentos referente a cada dimensão do instrumento. Sendo que, os escores correspondentes ao nível 3 (três) serão sempre os desejados pelas empresas, indicando o comportamento desejável; e o nível 0 (zero) indica que a empresa em um ou mais componentes deverá ser orientada a programar mudanças de comportamentos. Já os níveis 1 (um) e 2 (dois) indicam que ações para pequenos ajustes devam acontecer. Contudo, a idéia

Revista de Gestão Social e Ambiental - RGSA, São Paulo, v. 13, n. 3, p. 24-43, set./dez. 2019. 
geral é que a empresa reconheça positivamente a necessidade de incrementar ou afastar um comportamento habitual, a partir das informações recebidas e que possibilite a opção por oportunidades que possam levá-las a um nível mais elevado de gestão ambiental.

A segunda fase consistiu em testar o instrumento proposto. Nesse sentido foram selecionadas 30 pequenas e médias empresas localizadas no município de Fortaleza/Ceará, sendo 10 do segmento indústria, 10 do seguimento comércio e 10 do seguimento serviços. Foi feito um contato inicial pessoalmente do pesquisador com os gestores das empresas e posteriormente foi encaminhado o questionário via e-mail. Essa fase de coleta se deu na segunda quinzena de janeiro de 2019.

\section{PROPOSIÇÃO DO INSTRUMENTO DE MENSURAÇÃO}

Com base nas normas, leis e demais documentos que versam sobre práticas de preservação do meio ambiente (GRI, 2015; IBASE, 2006; ETHOS, 2016; AA1000APS, 2008; SEMA, 2017; SEUMA, 2017; IBAMA, 2017; ISO 14001, 2018), identificou-se nove indicadores/categorias de desempenho ambiental passíveis de adoção por pequenas e médias empresas. São elas:

- $\quad$ Categoria 1 - Conformidade - consiste em orientações de Leis e Regulamentos necessários para funcionamento da organização. Essa categoria subdividi-se em duas subcategorias, leis e regulamentos, contendo ao todo dez orientações (SEMA, 2017; SEUMA, 2017; IBAMA, 2017; NBR ISO 14001, 2018; AA1000, 2008; GRI, 2015);

- Categoria 2 - Insumos - consiste em orientações de como a organização deve tratar sobre o consumo de energia e sobre o tratamento e utilização de água. Também subdividi-se em duas subcategorias, energia e água, contendo ao todo oito orientações (GRI, 2015; ETHOS, 2016; ISO 14001, 2018; SEMA, 2017; SEUMA, 2017);

- Categoria 3 - Biodiversidade - consiste nos impactos significativos de atividades, produtos e serviços sobre a biodiversidade. Não possui subcategorias e contem quatro orientações (GRI, 2015; ETHOS, 2016; ISO 14001, 2008; IBAMA, 2017);

- Categoria 4 - Saídas - consiste como a organização trata a emissão de efluentes, de resíduos, de gases e de poluentes. Contém dez orientações sintetizadas em quatro subcategorias (GRI, 2015; ETHOS, 2016; SEMA, 2017; SEUMA, 2017; ISO 14001);

- $\quad$ Categoria 5 - Produtos e Serviços - essa categoria consiste no percentual de produtos e suas embalagens recuperadas. Não possui subcategorias e emite duas orientações (GRI, 2015; ISO 14001, 2008);

- Categoria 6 - Investimentos - consiste no total de investimentos e gastos com proteção ambiental. Com apenas uma orientação, não possui subcategorias (GRI, 2015; IBASE, 2006; ISO 14001, 2008);

- Categoria 7 - Avaliação Ambiental de Fornecedores - essa categoria consiste como a organização avalia seus fornecedores. Com duas orientações, não possui subcategorias (GRI, 2015; ISO 14001, 2008);

- Categoria 8 - Mecanismos de Queixas e Reclamações relacionadas a Impactos Ambientais - essa categoria consiste nas queixas e reclamações relacionadas a impactos ambientais. Possui apenas uma orientação, sendo assim, não possui subcategorias (GRI, 2015); e

- Categoria 9 - Resultados - essa categoria é composta pelos resultados de indicadores de desempenho da empresa relativos ao meio ambiente. Não possui subcategorias e contém seis orientações (IBASE, 2006; ETHOS, 2016).

De posse da primeira listagem de categorias e subcategorias, e com o auxílio de seis especialistas, estruturou-se uma segunda listagem dos indicadores/categorias contendo um conjunto de itens que totalizaram 36 questões, que irão orientar a construção do instrumento à ser aplicado na etapa seguinte. 
Buscou-se nessa etapa uma compatibilidade no total de itens selecionados por categoria. Sendo assim, para cada categoria foram propostos quatro questionamentos que seriam avaliados por meio de quatro afirmativas associadas a gestão ambiental (a, b, c e d). Para ilustrar, expõe-se a seguir no Quadro 2 o exemplo da categoria Conformidade.

Quadro 2 - Itens da categoria Conformidade

Conformidade - Analisa as práticas de gestão da empresa em relação ao cumprimento das exigências legais

1. As exigências legais necessárias para o funcionamento da empresa são conhecidas e mantidas atualizadas?

a) As exigências legais aplicáveis à empresa não são conhecidas.

b) Algumas exigências legais aplicáveis à empresa são conhecidas, mas não são mantidas atualizadas.

c) As exigências legais aplicáveis à empresa são conhecidas, mas não são mantidas atualizadas.

d) As exigências legais aplicáveis à empresa são conhecidas e mantidas atualizadas.

Com o conjunto de itens que caracterizam o instrumento de gestão ambiental definido, o próximo passo consistiu na seleção das dimensões-chave de gestão ambiental para pequenas e médias empresas. Nesse sentido, fez-se uso da análise estrutural visando a estruturação de uma reflexão coletiva por meio do método MICMAC. Dessa forma foi estruturado um quadro de dupla entrada, denominado matriz estrutural.

A matriz estrutural foi enviada por correio eletrônico (e-mail) para os mesmos seis especialistas que participaram anteriormente da definição dos indicadores/categorias. $O$ preenchimento do quadro consistia em quantificar o nível de adoção das práticas ambientais por meio de preenchimento de forma qualitativa, em que, para cada par de variáveis, o perito deveria colocar as seguintes questões: 1) Existe uma relação de influência direta entre a variável 1 e a variável 2? Se "Não" existe, deveria atribuir a nota "0". No caso de existir, deveria perguntar-se se esta relação de influência direta é fraca (1), moderada (2), forte (3) ou potencial (4).

De posse dos quadros preenchidos pelos seis especialistas, inseriu-se as notas dadas individualmente no Excel, buscando ao final, uma média das notas dos seis quadros preenchidos, já que para o uso do software MICMAC só se pode inserir um quadro com as notas atribuídas pelos especialistas. Ressalta-se que, originalmente pelo método se teria que chegar a um consenso em relação as notas atribuídas às variáveis. No entanto, buscou-se essa alternativa, devido a dificuldade de reunir todos os especialistas em um mesmo local. A inserção das notas atribuídas às variáveis, resultou na indicação de seis variáveis-chave e na exclusão de três variáveis. As seis variáveis tidas como chave são: conformidade; investimentos; saídas; mecanismos de queixas e reclamações relacionadas a impactos ambientais; produtos e serviços; e insumos. E as três variáveis excluídas foram: fornecedores, resultados e biodiversidade.

Portanto, com a sugestão de retirada de três variáveis, ficou definido as dimensões que compuseram o instrumento que vai possibilitar avaliar o nível de gestão ambiental das pequenas e médias empresas, conforme exposto no Quadro 3.

Quadro 3 - Descrição das dimensões que irão compor o instrumento

\begin{tabular}{|l|l|}
\hline \multicolumn{1}{|c|}{ Categoria } & \multicolumn{1}{|c|}{ Descrição } \\
\hline Conformidade & $\begin{array}{l}\text { Analisa as práticas de gestão da empresa em relação ao cumprimento das } \\
\text { exigências legais. }\end{array}$ \\
\hline Investimentos & $\begin{array}{l}\text { Analisa as práticas de investimentos da gestão ambiental com foco na } \\
\text { sustentabilidade e preservação do meio ambiente. }\end{array}$ \\
\hline Saídas & $\begin{array}{l}\text { Analisa as práticas de gestão da empresa para gerir as emissões de efluentes, } \\
\text { resíduos, gases e poluentes em busca da saúde humana. }\end{array}$ \\
\hline $\begin{array}{l}\text { Mecanismos de queixas e } \\
\text { reclamações relacionadas } \\
\text { a impactos ambientais }\end{array}$ & $\begin{array}{l}\text { Analisa as práticas de gestão da empresa em relação as queixas e reclamações } \\
\text { relacionados a impactos ambientais por meio do tratamento das reclamações, da } \\
\text { avaliação e utilização dessas informações para a melhoria continua. }\end{array}$ \\
\hline Produtos e serviços & $\begin{array}{l}\text { Analisa as práticas de gestão da empresa em relação a extensão da mitigação de } \\
\text { impactos ambientais de produtos e serviços. }\end{array}$ \\
\hline Insumos & Analisa as práticas de gestão da empresa em relação ao consumo de energia e água. \\
\hline
\end{tabular}


Buscando uma representação gráfica que pudesse visualmente melhor representar as dimensões que compõem o instrumento de mensuração do nível de gestão ambiental das pequenas e médias empresas, elaborou-se a Figura 1, denominada de Apiário Organizacional do Meio Ambiente, sendo que cada um dos eixos representa uma dimensão.

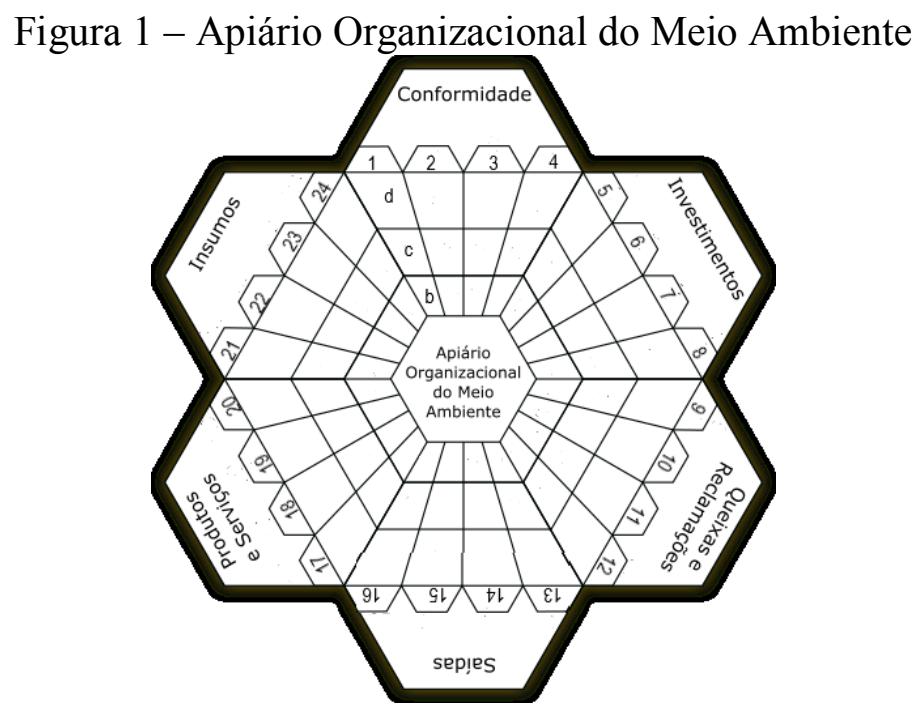

Para cada dimensão do Apiário existem quatro questionamentos, que são avaliados por meio de uma escala de 0 a 3 , sendo:

- $\quad 0$ - representado pela alternativa "a" e sinalizando ser uma prática que não faz parte do dia-a-dia da empresa. Como o "0" não pontua, na Figura 1 a empresa permanece no centro do Apiário Organizacional;

- $\quad 1$ - é representado pela alternativa " $b$ " e sinaliza ser uma prática que às vezes faz parte do dia-a-dia da empresa. A empresa já consegue atingir o primeiro degrau na adoção de práticas de gestão ambiental na Figura 1;

- $\quad 2$ - é representado pela alternativa "c" e sinaliza que a prática quase sempre faz parte do dia-a-dia da empresa. Com esse nível de adoção em uma prática a empresa já atingi o segundo degrau na Figura 1; e o

- $\quad 3$ - é representado pela alternativa “d”, em que a empresa afirma ser uma prática que verdadeiramente faz parte do dia-a-dia. E nessa situação a empresa atingi o topo do Apiário, simbolizado pela letra "d" na Figura 1.

Adicionalmente, buscando um nivelamento individual para o somatório das respostas na escala de 0 a 3, propõe-se a divisão da pontuação máxima em três níveis, sendo o nível mais baixo denominado "negativo", cuja pontuação vai de 0 a 24 pontos; já o segundo nível é denominado de "intermediário", cuja pontuação vai de 25 a 48 pontos; e o terceiro e mais elevado nível é denominado de "positivo", cuja pontuação vai de 49 a 72 pontos, conforme exposto no Quadro 4.

Quadro 4 - Nivelamento individual para o somatório das respostas na escala de 0 a 3

\begin{tabular}{|l|l|l|}
\hline \multicolumn{1}{|c|}{ Pontuação } & \multicolumn{1}{|c|}{ Indicativo } & \multicolumn{1}{c|}{ Descrição } \\
\hline Até 24 pontos & Negativo & $\begin{array}{l}\text { A empresa se preocupa com muitos poucos aspectos da gestão ambiental. } \\
\text { Ao aplicar o Instrumento, encontrará inúmeras e importantes } \\
\text { oportunidades para melhorar. }\end{array}$ \\
\hline 25 a 48 pontos & Intermediário & $\begin{array}{l}\text { A empresa se preocupa com alguns aspectos da gestão ambiental. Ao } \\
\text { aplicar o Instrumento, encontrará inúmeras e importantes oportunidades } \\
\text { para melhorar e aumentar as chances de sucesso. }\end{array}$ \\
\hline 49 a 72 pontos & Positivo & $\begin{array}{l}\text { A empresa já se preocupa com aspectos importantes da gestão ambiental } \\
\text { e, encontrará muitas oportunidades para melhorar, aumentando suas } \\
\text { chances de sucesso. }\end{array}$ \\
\hline
\end{tabular}


Graficamente se teria mais ou menos as representações expostas no Quadro 5. Quanto mais pintado/haxurado for o Apiário, melhor o perfil do estilo de gestão ambiental da (s) empresa (s). Quanto mais espaços existirem na figura, pior é o perfil do estilo de gestão ambiental. A análise do Apiário possibilita verificar as deficiências ou qualidades por dimensão avaliada (Quadro 5).

Quadro 5-Nivelamento individual para o somatório das respostas na escala de 0 a 3

\begin{tabular}{c|c}
$\begin{array}{c}\text { Nível Negativo } \\
\text { (0 a 24 pontos) }\end{array}$ & $\begin{array}{c}\text { Nível Intermediário } \\
\text { (25 a 48 pontos) }\end{array}$ \\
\hline (49 a 72 pontos)
\end{tabular}

A ideia geral é que a empresa ou um grupo de empresas reconheça positivamente a necessidade de incrementar ou afastar uma prática habitual, a partir das informações recebidas e que possibilite a opção por oportunidades que possa levá-la a uma gestão com mais responsabilidade ambiental.

Vale ressaltar ainda, que as respostas ao instrumento podem ser analisadas de forma individual ou coletiva, explorando, por exemplo, as escalas de maior e de menor adoção para cada uma das dimensões, discutindo qual das dimensões é mais adotada no cotidiano das empresas, e qual a menos observadas por elas.

\section{TESTE DE VIABILIDADE DO APIÁRIO ORGANIZACIONAL DO MEIO AMBIENTE}

Para testar a viabilidade do Apiário Organizacional do Meio Ambiente, ele foi aplicado em 30 pequenas e médias empresas dos seguimentos de indústria, comércio e serviço, localizadas no município de Fortaleza/Ceará.

Visando ilustrar a análise individual (por empresa) foram selecionadas as respostas de três empresas do segmento comércio - Empresa 1, Empresa 2 e Empresa 3, conforme exposto no Quadro 6. 
Quadro 6 - Apiário Organizacional do Meio Ambiente - Análise individual

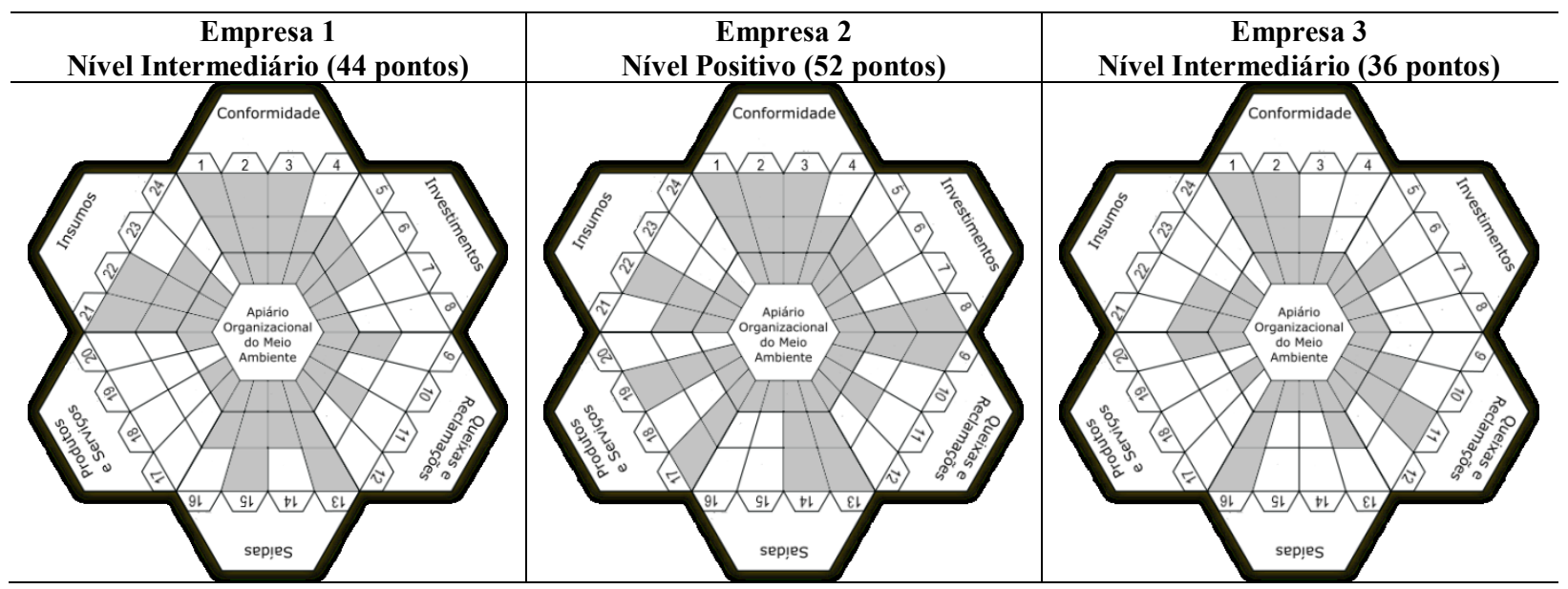

Atentando para o Quadro 6 observa-se que, tanto a Empresa 1 quanto a Empresa 3 estão no nível intermediário quanto ao perfil ideal do estilo de gestão ambiental, com 44 pontos e com 36 pontos respectivamente. Já a Empresa 2, está no nível positivo, com 52 pontos.

Quanto as dimensões, observa-se que a dimensão Conformidade é a que está mais pintada nas três empresas investigadas, sinalizado ser esta dimensão a mais presente nas empresas. $\mathrm{Na}$ categoria "Conformidade" um dos itens avaliado na sub-categoria "Regulamentos" é sobre o cadastro de produtos agrotóxicos por parte das empresas brasileiras, e nesse sentido, Hrdlicka (2009) ressalta que o Brasil é um dos maiores mercados de agrotóxicos devido às suas condições de clima tropical que favorece agentes causadores de doenças ou desenvolvimento de pragas. Fato este que possivelmente pode explicar o foco dado pelas empresas nessa categoria.

A segunda dimensão mais presente nas empresas foi "Saídas". Dentre os itens avaliados nessa dimensão tem-se a "emissão de resíduos". E nesse sentido, Martins, Silva e Carneiro (2017) ressaltam que no Brasil, em 2010, após mais de 20 anos de discussões no Congresso Nacional, foi instituída a Lei 12.305, que versa sobre a Política Nacional de Resíduos Sólidos (PNRS), que é responsável por reger o processo de disposição final do lixo. Além de estabelecer, dentre outras coisas, os princípios de responsabilidade compartilhada sobre a destinação dos produtos ao final de sua vida útil, a lei estimula a adoção de logística reversa de materiais de coleta seletiva e adequação de ambientes em que são depositados os rejeitos incapazes de serem reutilizados ou reciclados.

$\mathrm{E}$ as duas dimensões menos haxuradas foram "Produtos e Serviços" e "Insumos", sinalizando que estas categorias precisam sem melhor apreciadas pelas empresas investigadas.

Em relação aos Insumos, Menezes, Gomes e Tometich (2013) ressaltam que as inovações em produtos ou processos tem sua participação na redução do impacto das atividades empresariais no meio ambiente, como por exemplo ajudar na redução da emissão de gases causadores do efeito estufa e liberação de resíduos, bem como reduzir os gastos das empresas com energia, água, material, entre outros insumos.

O uso de recursos (consumo de energia e água), humanos e organizacionais (qualificação da mão de obra, treinamento e cultura organizacional) pode influenciar o desempenho ambiental da empresa (Jabbour, 2015). Isso pode ser explicado pela contínua conscientização dos colaboradores e das organizações, por economia na utilização de recursos naturais, com a modernização dos equipamentos e dos processos, entre outros fatores (Oliveira, Serra, \& Salgado, 2010).

$\mathrm{Na}$ análise coletiva, das 30 empresas participantes da pesquisa, dez são do segmento indústria, dez do comércio e dez do segmento serviço.

Observa-se no Quadro 7 que, as empresas do segmento indústria apresentaram uma melhor avaliação no contexto geral, pois o Apiário encontra-se mais pintado. Na sequência tem-se o segmento serviço; e por último o segmento comércio. 
Quadro 7 - Apiário Organizacional do Meio Ambiente - Análise Coletiva

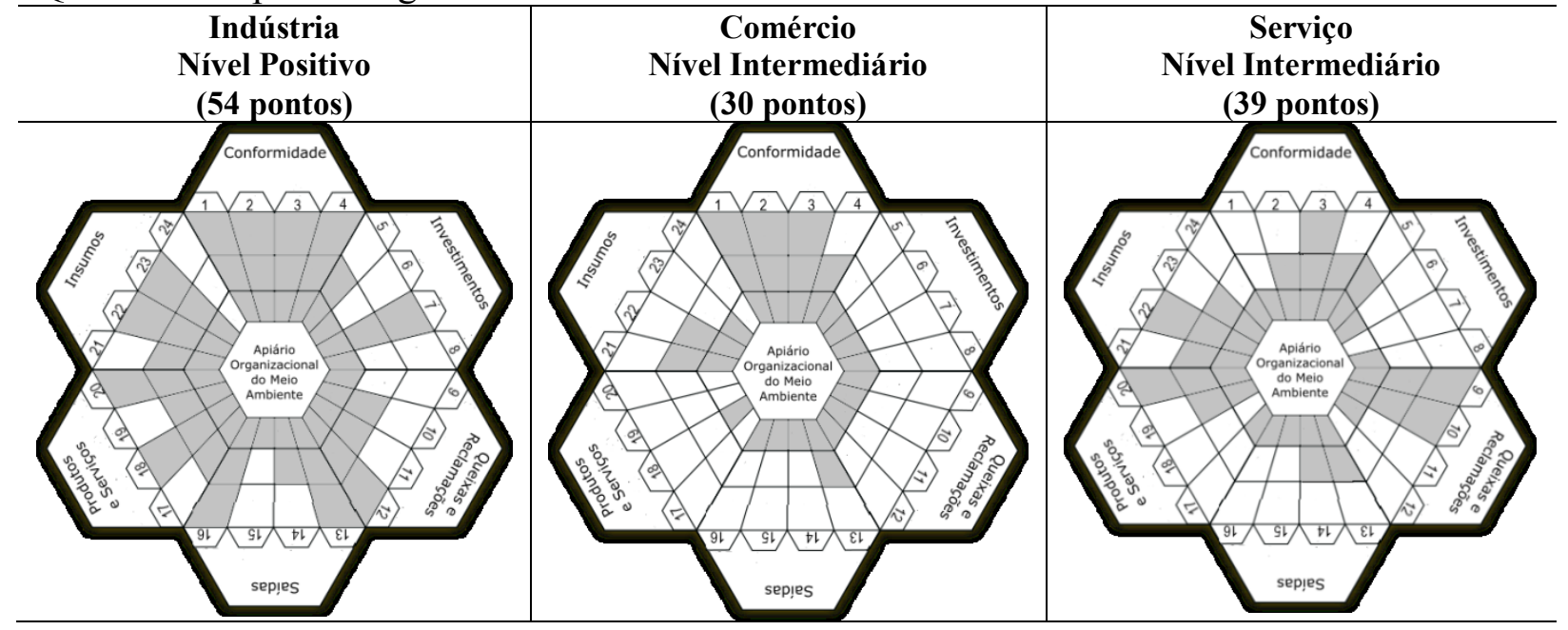

Atentando para as dimensões, observa-se que além da dimensão "Conformidade", outra dimensão que também apresentou-se de forma positiva nas empresas investigadas foi "Insumos". E nesse sentido, Fonseca (2017) chama atenção para a indústria de produtos lácteos, em que buscou avaliar a ecoeficiência do consumo de água e energia na indústria de produtos lácteos e $\mathrm{o}$ licenciamento ambiental, no estado da Bahia. O autor concluiu que os laticínios licenciados no estado da Bahia são menos eficientes na utilização dos insumos de água e energia em relação à indústria nacional, da mesma forma que esta em relação à indústria internacional (benckmarking). Indica-se que esse tipo de abordagem ainda não é uma iniciativa do Órgão Ambiental e que o conceito de ecoeficiência não está incorporado nas análises do licenciamento ambiental, no Brasil.

Já Magala (2001) chama atenção apara o setor têxtil que atraiu a atenção de ambientalistas, em todo o mundo, por seu alto consumo de água, produtos químicos, energia e liberação de efluentes contaminados ao final do processo, causando intensa poluição, além da poluição atmosférica e sonora, proveniente das fases de produção.

É pertinente também ressaltar a quantidade de respostas no item "d" atribuídas as afirmativas, em que a empresa afirma ser uma prática que verdadeiramente faz parte do seu dia-adia. Das vinte e quatro perguntas o seguimento industrial obteve um resultado com 11 respostas "d", o seguimento de serviço apresentou um resultado com cinco respostas "d", e o seguimento de comércio obteve três resultados com respostas d.

Em média, as empresas do segmento indústria, comércio e serviços apresentaram pontuação que as coloca no nível intermediário (41 pontos), sinalizando que as empresas, apesar de estarem em um nível médio precisam programar mudanças de comportamento para alguns dos indicadores, tendo em vista a baixa pontuação apresentada por exemplo, no indicador "investimento".

O Apiário Organizacional do Meio Ambiente possibilitou mensurar o nível de gestão ambiental das empresas, dando assim, um panorama da atual situação e abrindo espaço para que as empresas busquem uma melhoria continua no nível de gestão ambiental. Sendo assim. o instrumento proporciona não somente a auto avaliação como também serve de guia para que as empresas possam evoluir, de acordo com cada dimensão.

\section{CONCLUSÃO}

Os resultados possibilitaram concluir, em relação ao primeiro objetivo específico identificar as dimensões-chave de preservação do meio ambiente no contexto organizacional das pequenas e médias empresas - que seis dimensões são consideradas chave para mensurar o nível de gestão ambiental de pequenas e médias empresas. São elas: conformidade; investimentos; saídas; 
mecanismos de queixas e reclamações relacionadas a impactos ambientais; produtos e serviços; e insumos.

Quando ao segundo objetivo específico - testar a viabilidade do instrumento proposto concluiu-se que, as dimensões e itens do instrumento proposto possibilitam mensurar o nível de gestão ambiental das pequenas e médias empresas de qualquer seguimento, tendo em vista a sua aplicabilidade em empresas do segmento indústria, comércio e serviços. Fortalecendo assim, a credibilidade do instrumento e seu construto. A gestão ambiental não têm extensão limitada, ao contrário, possui uma dimensão que ultrapassa os limites de qualquer tipo de empresa ou seguimento. Por conta disso, o Apiário Organizacional do Meio Ambiente deve ser reconhecido independentemente de seguimento, tamanho da empresa e mercado que atua.

Já em relação ao terceiro objetivo específico - avaliar o perfil do estilo de gestão ambiental de pequenas e médias empresas dos segmentos indústria, comércio e serviço - concluiu-se que, em geral as empresas do segmento indústria, comércio e serviços, apresentaram pontuação que as coloca no nível intermediário (41 pontos), sinalizando que as pequenas e médias empresas, apesar de apresentarem um perfil do estilo de gestão ambiental intermediário, precisam programar mudanças de comportamento para alguns dos indicadores, tendo em vista a baixa pontuação apresentada por exemplo, no indicador "investimento".

Portanto, concluiu-se a pesquisa com a proposição de um instrumento de mensuração do nível de gestão ambiental de pequenas e médias empresas, denominado Apiário Organizacional do Meio Ambiente.

Ao ser criado, o Apiário Organizacional do Meio Ambiente assumiu o compromisso de promover uma ferramenta que permite um diagnóstico objetivo e a medição do nível de gestão ambiental pelos gestores e por acadêmicos. É preciso compreender as organizações que se encontram num complexo mundo de relações e que, por conta disso, o posicionamento estratégico frente a esse imbricado de relações tem que corresponder a uma percepção muito clara frente aos temas que representam grandes ameaças e colocam em risco a vida no planeta.

Vale ressaltar que, este instrumento não busca culpados e sim mostrar a realidade e o que a empresa precisa evoluir no desenvolvimento sustentável, auxiliando na tomada de decisão no desenvolvimento de políticas ambientais. Estas categorias separadamente não explicam as praticas da gestão ambiental como um todo, mas quando analisadas de forma integrada revelam um significado mais amplo sobre o nível de gestão ambiental organizacional.

Como contribuição tem-se a disponibilização de um instrumento de mensuração do nível de gestão ambiental de pequenas e médias empresas, com utilidade tanto para os gestores, quanto para acadêmicos, que buscam propor decisões na avaliação de empresas considerando os recursos utilizados e ações realizadas sob o ponto de vista de sustentabilidade. Acredita-se que o efeito prático e estético do recurso gráfico do Apiário Organizacional do Meio Ambiente (e, talvez, o poder do símbolo), revelando visualmente o perfil do estilo de gestão ambiental organizacional, irá atrair gestores e pesquisadores a utilizarem este instrumento, sem preocupação com as características psicométricas do mesmo.

Como recomendações para estudos futuros, sugere-se que outros trabalhos com a mesma temática sejam desenvolvidos, considerando as orientações de outros países. Bem como, sejam desenvolvidas outras investigações utilizando o Apiário Organizacional do Meio Ambiente, para analisar o nível de gestão ambiental de pequenas e médias empresas de outras cidades/regiões do Brasil, a fim de que, se possa cada vez mais, divulgar práticas de gestão com o intuito de buscar ações efetivas que minimizem o impacto causado pelas empresas ao planeta.

\section{REFERÊNCIAS}

Accountability. AA1000. (2008). AccountAbility Framework Standard. Disponível em: http:// http://www.accountability.org/standards/. Acesso em: 14 nov. 2017. 
Apiário organizacional do meio ambiente: instrumento de mensuração do nível de gestão ambiental

Abreu, M. C. S.; Figueirêdo JR., H. S.; \& Varvakis, G. (2004). As pressões ambientais da estrutura da indústria. $R A E, 3(2)$, jul./dez.

Acquaah, M. (2003). Corporate management, industry competition and the sustainability of firm abnormal profitability. Journal of Management and Governance, 7(1), 57-85.

Andrade, A.; \& Rossetti, J. P. (2012). Governança corporativa: fundamentos, desenvolvimento e tendências. 3.ed., São Paulo, Atlas, 608 p.

Bansal, P. (2005). Evolving sustainably: A longitudinal study of corporate sustainable development. Strategic Management Journal, 26(3), 197-218.

Bardin, L. (2011). Análise de Conteúdo. Lisboa: Edições 70.

Berrone, P.; \& Gomez-Mejia, L.R. (2009). Environmental performance and executive compensation: an integrated agency-institutional perspective. Academy of Management Journal, 52(1), 103-126.

Bertolini, G. R. F. \& Possamai, O. (2005). Proposta de instrumento de mensuração do grau de consciência ambiental, do consumo ecológico e dos critérios de compra dos consumidores. Revista de Ciência e Tecnologia, 13(25/26), 17-25.

Bleischwitz, R. (2003). Cognitive and institutional perspectives of eco-efficiency Ecological. Economics, (46), 453-467.

Campos, L. M. S., \& Melo, D. A. (2008). Indicadores de desempenho dos Sistemas de Gestão Ambiental (SGA): uma pesquisa teórica. Produção, 18(3), 540-555.

Ceretta, P.S. et al. (2009). Desempenho financeiro e a questão dos investimentos sócio-ambientais. RGSA - Revista de Gestão Social e Ambiental, 3(3), 72-84.

Clarkson, et al. (2011). Does it really pay to be green? Determinants and consequences of proactive environmental strategies. Journal of Accounting and Public Policy, 30(2), 122-144.

Collis, J., \& Hussey, R. (2005). Pesquisa em administração: um guia prático para alunos de graduação e pós-graduação.Porto Alegre: Bookman.

Conyon, M. J., \& He, L. (2011). Executive compensation and corporate governance in China. Journal of Corporate Finance, 17(4), 1158-1175.

Corazza, R. I. (2016). Gestão ambiental e mudanças da estrutura organizacional. RAE-Eletrônica, 2(2), jul./dez.

Dasgupta, S. et al. (2006). Disclosure of environmental violations and stock market in the Republic of Korea. Ecological Economics, 58(4), 759-777.

Deponti, C. M., Córdula, E., \& Azambuja, J. L. B. (2002). Estratégia para construção de indicadores para avaliação da sustentabilidade e monitoramento de sistemas. Agroecologia e Desenvolvimento Rural Sustentável, 3(4), 44-52.

Diniz, M. J. T. (2008). A Dinâmica das Inovações nas Empresas do Pólo Industrial de Manaus: um novo momento relacionado aos constrangimentos ambientais a partir do ano 2000. 2008. 210f. Tese (Doutorado em Desenvolvimento Sustentável)-Programa de Desenvolvimento Sustentável do Trópico Úmido, do Núcleo de Altos Estudos Amazônicos da Universidade Federal do Pará, Belém: UFPA.

ETHOS. Instituto. (2016). Indicadores ETHOS para negócios sustentáveis e responsáveis. São Paulo. 
ETHOS. Instituto. (2004). Indicadores Ethos. Disponível em:

http://www3.ethos.org.br/conteudo/indicadores-ethos-publicacoes/\#.WgzJ5mhSzDe. Acesso em: 14 nov. 2017.

Fernandes, D. R. (2004). Uma contribuição sobre a construção de indicadores e sua importância para a gestão empresarial. Revista FAE, Curitiba, 7(1), 1-18, jan./jun.

Fernández- Kranz, D., \& Santaló, J. (2010). When necessity becomes a virtue: the effect of product market competition on corporate social responsibility, Journal of Economics \& Management Strategy, 19(2), p. 453-487.

Fonseca, J. C. J. (2017). Análise de ecoeficiência do consumo de água e energia na indústria de laticínios no licenciamento ambiental no estado da Bahia. 2017. 80 f. Dissertação (Mestrado em Engenharia Civil e Ambiental) - Universidade Estadual de Feira de Santana, Feira de Santana.

FQN - Fundação Nacional de Qualidade. (2016). Sistema de Indicadores. São Paulo, SP.

Galdeano-Gómez, E., Céspedes-Lorente, J., \& Martínez-Del-Río, J. (2008). Environmental performance and spillover effects on productivity: evidence from horticultural firms. Journal of Environmental Management, 88(4), 1552-1561.

Goellner, G. E., Jappur, R. F., \& Prado, G. P. (2019). Análise de indicadores do sistema de gestão ambiental das concessionárias de veículos toyota no estado de Santa Catarina após a certificação iso 14001. Revista Gestão \& Sustentabilidade Ambiental, 8(1), 60-77.

Godard, O. (1993). Stratégies industrie lle set conventions d'environnement: de l'univers tabilisésaux univers controversés. In: INSEE. Environnement et économie. Paris.

GRI. Global Reporting Iniciative. (2015). Diretrizes para relatórios de sustentabilidade. 2013-2015 ver. 4.0. Disponível em: www.globalreporting.org. Acesso em: 14 nov. 2017.

Haigh, N., \& Griffths A. (2009). The natural environment as a primary stakeholder: the case of climate change. Business Strategy and the Environment, 18(1), 347-359.

Hrdlicka, H. A. (2009). As boas práticas de gestão ambiental e a influência no desempenho exportador: um estudo sobre as grandes empresas exportadoras brasileiras. 2009. 283f. Tese (Doutorado em Administração) - Departamento de Administração da FEAC da Universidade de São Paulo. São Paulo: UPS.

IBAMA, Instituto Brasileiro do Meio Ambiente e dos Recursos Naturais Renováveis. (2017). Carta de Serviços ao Cidadão.

IBASE, Instituto Brasileiro de Análise Sociais e Econômicas. (2003). Publique Seu Balanço Social. Disponível em: $<$ http://www.balancosocial.org.br/cgi/cgilua.exe/sys/start.htm?sid=2>. Acesso em: 14 nov. 2017.

Jabbour, C. J. C. (2015). Environmental training and environmental management maturity of Brazilian companies with ISO14001: Empirical evidence. Journal of Cleaner Production, 96(1), 331-338. doi:10.1108/02635570910948623

Jansson, Å., Nilsson F., \& Rapp B. (2000). Environmentally driven mode of business development: a management control perspective. Scandinavian. Journal of Management, 16(1), 305-333.

Liu, X., Lu, J., Chizema, A. (2013). Top executive compensation, regional institutions and Chinese OFDI. Journal of World Business, 49, 143-155.

Luo, Y. (2006). Global Dimensions of Corporate Governance. Malden:Blackwell Publishing.

Mahadeo, J.D., Oogarah-Hanuman, V., \& Soobaroyen, T. (2011). A Longitudinal Study of Corporate Social Disclosures in a Developing Economy. Journal of Business Ethics, 104. 
Apiário organizacional do meio ambiente: instrumento de mensuração do nível de gestão ambiental

Marimon, F.; CasadesúS, M.; Heras, I. (2010). Certification intensity level of the leading nations in ISO 9000 and ISO 14000 standards. International Journal of Quality \& Reliability Management, 27(9), 1002-1020, doi:10.1108/02656711011084800

Marimon, F.; Llach, J.; Bernardo, M. C. (2011). Comparative analysis of diffusion of the ISO 14001 standard by sector of activity. Journal of Cleaner Production, 19(15).

Mårtensson, K., \& Westerberg, K. (2007). How to transform local energy systems toward bioenergy? Three strategy models for transformation. Energy Policy, 35(1).

Martins, L. O. S., Silva, L. T., \& Carneiro, R. A. F. (2017). Análise da Viabilidade Econômica e Financeira da Implantação de Usina de Geração de Energia a partir de Resíduos Sólicos Urbanos no Município de Santo Antônio de Jesus - BA. Revista Livre de Sustentabilidade e Empreendedorismo, 2(2), 142-166, abr./jun.

Mcwilliams, A., Siegel, D. S., \& Wright, P. M. (2006). Corporate social responsibility: strategic implications. Journal of Management Studies, 43(1), 1-18.

Melo, T., \& Garrido- Morgado, A. (2012). Corporate reputation: a combination of social responsibility and industry. Corporate Social Responsibility and Environmental Management, 19(1), 11-31.

Menezes, U., Gomes, C. \& Tometich, P. (2013). As práticas de inovação tecnológica orientadas para o desenvolvimento sustentável das indústria químicas e o seu desempenho. Disponível em: < https://www.ufrgs.br/sustentabilidade/?p=233>. Acesso em: 10 fev. 2019.

Miller, G. (2001). The development of indicators for sustainabletourism: results of a Delphi survey of tourism researchers.Tourism Management, 22(4), 351-362.

Neville, B. A., Bell, S. J., \& Menguç, B. (2005). Corporate reputation, stakeholders and the social performance-financial performance relationship. European Journal of Marketing, 39(9/10), 11841198.

Nossa, V. (2002). Disclosure ambiental: uma análise do conteúdo dos relatórios ambientais de empresas do setor de papel e celulose em nível internacional. 2002. Tese de Doutorado. Universidade de São Paulo.

Oliveira, O. J. De, Serra, J. R., \& Salgado, M. H. (2010). Does ISO 14001 work in Brazil? Journal of Cleaner Production, 18(18), 1797-1806.

Paillé, P. et al. (2014). The impact of human resource management on environmental performance: An employee-level study. Journal of Business Ethics, 121(3), 451-466.

Patton, M. (2002). Qualitative research and evaluation methods. Thousand Oaks: Sage.

Paulraj, A. (2009). Environmental motivations: a classification scheme and its impact on environmental strategies and practices. Business Strategy and the Environment, 8(1).

Porter, M.E., \& Kramer, M.R. (2006). Strategy and Society: The Link Between Competitive Advantage and Corporate Social Responsibility. Harvard Business Review, 84(12).

Porter, M. E., \& Van Der Linde, C. (1995). Toward a new conceptionoftheenvironmentcompetitionrelationship. Journal of Economic Perspectives, 8(4), 97-118.

Rodrigues, M. (2014). Contrasting realities: corporate environmental disclosure and stakeholderreleased information.Accounting, Auditing \& Accountability Journal, 27(1).

Rodrigues, A. M. et al. (2015). Avaliação de desempenho ambiental industrial: elaboração de um referencialmetodológico/Evaluation of industrial environmental performance: elaboration of a methodological framework. Revista Produção Online, 15(1), 101. 
Santana, A. C. (2008). Educação Ambiental e as empresas: um caminho para a sustentabilidade. Educação ambiental em ação, (24).

Santos, C. P. (2007). A Educação Ambiental: um estudo de caso no município de Vitória da Conquista - BA. 2007. 113 f. Mestrado (Programa Regional de Pós-graduaçao em Desenvolvimento e Meio Ambiente)-UESC, Ilhéus-BA.

SEMACE. Secretaria de Meio Ambiente do Ceará. (2017). Disponível em: $<\mathrm{http}: / / \mathrm{http}: / / \mathrm{www}$. semace.ce.gov.br/>. Acesso em: 14 nov. 2017.

SEUMA, Secretaria de Urbanismo e Meio Ambiente de Fortaleza. (2017). Disponível em: http://portal.seuma.fortaleza.ce.gov.br/fortalezaonline/portal/. Acesso em: 14 nov 2017.

Sharfman, M. P., \& Fernando, C. S. (2008). Environmental risk management and the cost of capital. Strategic Management Journal, 29(6), 569-592.

Silva, A. P. F. et al. (2012). Indicadores Sociais: um estudo realizado nos Balanços Sociais de empresas que receberam o Selo IBASE. Reunir, 2(1), 72-86, jan./abr..

Singh, N., Jain, S., \& Sharma, P. (2015). Motivations for implementing environmental management practices in Indian industries. Ecological Economics, 109, 1-8.

Spence, M. (1984). Cost reduction, competition, and industry performance. Econometrica, 52(1), 101-121.

Strauss, A. L., \& Corbin, J. (2008). Pesquisa qualitativa: técnicas e procedimentos para o desenvolvimento de teoria fundamentada. Porto Alegre: Artmed.

Tachizawa, T. (2010). Gestão Ambiental e Responsabilidade Social Corporativa: estratégias de negócios focadas na realidade brasileira. São Paulo, Atlas, 442 p.

Tang, Z., \& Tang, J. (2013). Can the media discipline Chinese firms' pollution behaviors? The mediating effects of the public and government. Journal of Management.

To, W. M., \& Lee, P. K. C. (2014). Diffusion of ISO 14001 environmental management system: Global, regional and country-level analyses. Journal of Cleaner Production, 66.

Verrecchia, R. E. (2001). Essays on disclosure. Journal of Accounting and Economics, Amsterdam, 32(1-3), 97-180, December.

Vieira, A. R. (2016). Educação ambiental nas empresas: análise de caso em uma fábrica de cimento no Distrito Federal.

Villiers, C., Naiker, V., \& Van Staden, C. J. (2011).The effect of board characteristics on firm environmental performance, Journal of Management, 37(6), 1636-1663.

Wrigth, J. T. C., \& Giovinazzo, R. A. (2000). Delphi - uma ferramenta de apoio ao planejamento prospectivo. Caderno de Pesquisa em Administração, São Paulo, 1(12).

$\mathrm{Xu}, \mathrm{X}$. et al. (2014). The impact of corporate environmental violation on shareholders' wealth: a perspective taken from media coverage. Business Strategy and the Environment.

Zhang, R. et al. (2010). Corporate philanthropic giving, advertising intensity, and industry competition level. Journal of Business Ethics, 94(1), 39-52.

Zou, H. et al. (2015). How do environmental violation events harm corporate reputation? Business Strategy and the Environment, 24(8), 836-854, December.

Zou,H.L., Zeng,S.X., \& Lin,H. (2015).Top executives' compensation, industrial competition, and corporate environmental performance: evidence from China. Management Decision, 53(9). 
Apiário organizacional do meio ambiente: instrumento de mensuração do nível de gestão ambiental

RGSA adota a Licença de Atribuição CC BY do Creative Commons (https://creativecommons.org/licenses/by/4.0/).

Revista de Gestão Social e Ambiental - RGSA, São Paulo, v. 13, n. 3, p. 24-43, set./dez. 2019. 